\title{
Medicolegal basics and update on transvaginal mesh in Canada
}

\author{
Brock Hengel, JD'; Blayne Welk, MD'; Richard J. Baverstock, $M D^{3}$
}

'Juris Doctor candidate, University of Ottawa, Faculty of Law-Common Law Section, Ottawa, ON; ${ }^{2}$ Department of Surgery, Western University, London, ON; ${ }^{3}$ vesia [Alberta Bladder Centre] and Department of Surgery, University of Calgary, Calgary, AB; Canada

Cite as: Can Urol Assoc J 2017;11 (6Suppl2):S108-11. http://dx.doi.org/10.5489/cuaj.4580

See related commentary on page 5112 .

\section{Abstract}

In recent years, midurethral slings (MUS) and transvaginal mesh procedures have experienced blazing growth and popularity. However, the US Food and Drug Administration (FDA) and Health Canada regulatory advisories threw water on that fire and created a confusing environment surrounding their continued usage. MUS usage has continued in Canada and transvaginal mesh kits for pelvic organ prolapse have become a rarity. Several large organizations (the Society of Urodynamics, Female Pelvic Medicine and Urogenital Reconstruction [SUFU], the American Urogynecologic Society [AUGS], and the Canadian Urological Association [CUA]) have developed "mesh statements" to clarify the issues surrounding mesh for patients and medical professionals; however, often the legal system sees things differently in either individual cases or class action lawsuits. In this update, some medicolegal basics are outlined and Canadian context on legal proceedings are highlighted. This summary does not constitute legal advice and physicians should contact experts in legal matters for help with consents, complaints, litigation, or questions.

\section{Introduction}

Midurethral slings (MUS) and transvaginal mesh procedures are innovative and effective ways to treat stress urinary incontinence (SUI) and pelvic organ prolapse (POP). However, MUS procedures and transvaginal mesh products have recently become controversial, fuelled by the Food and Drug Administration (FDA), ${ }^{1}$ Health Canada ${ }^{2}$ warnings, and media and internet information. Many societies, like the Society of Urodynamics, Female Pelvic Medicine and Urogenital Reconstruction (SUFU), American Urogynecologic Society (AUGS), ${ }^{3}$ American Urological Association (AUA), ${ }^{4}$ and Canadian Urological Association $(\mathrm{CUA})^{5}$ have developed "mesh statements" to address the controversies of vaginal mesh for patients and medical professionals; however, recent lawsuits surrounding MUS malpractice and manufacturer liability have likely compounded the controversy. The purpose of this article is to provide an overview of MUS medicolegal considerations and to provide an update on the relevant jurisprudence in Canada.

\section{Medicolegal basics}

Before discussing transvaginal mesh, we will provide a short overview of "negligence." Readers are directed to the useful reference of "Cases and Materials on the Law of Torts" for further information. ${ }^{6}$ In tort law (a civil wrong by one person against another person), negligence covers a broad range of unintentional, yet reasonably foreseeable behaviours that cause others harm. There are several elements that a plaintiff, or person alleging negligence, must prove on a balance of probabilities to establish negligence. The first element that needs to be proved is whether a duty of care existed between the defendant and plaintiff, which determines whether negligence is even possible between the parties. A series of factors assist this analysis, including proximity and foreseeability of risk. The common law recognizes predetermined duty of care categories, such as doctors to patients, motor vehicle drivers to everyone in their vicinity, and pubs to patrons.

The next element that must be established is standard of care and the plaintiff must prove it was breached. Standard of care refers to how a reasonable person would act in the situation that gave rise to the alleged negligence. The standard is driven by reasonableness and raises both questions of law and fact. After the court establishes the standard of care or how a reasonable person would act, the defendant's conduct is measured against that standard to determine if a breach occurred. For doctors and other skilled professionals, the standard of care is modified: a court will set the standard by considering how another reasonable doctor in the same speciality would act in the same circumstances. If it can be established that the defendant doctor's work fell below the accepted practice of another reasonable colleague, then they 
will be held liable for any damage that results. Conversely, a doctor will not be negligent if a court finds they conducted their professional duties in line with standards that are regarded as being "recognized and respectable practice[s] of the profession." It is important to note that the standard is measured at the time of the alleged negligent act and not at trial. During the analysis courts afford some buffer room and realize that examining medical negligence in hindsight can lead to unrealistic assessments. Thus, it can be understood that for defendants (doctors) the breach of standard of care can be difficult for plaintiffs to satisfy, especially if the professional is highly specialized and colleagues are reluctant to testify.

The next element that needs to be established is that the defendant's breached standard of care caused actual loss to the plaintiff. Legal causation has a much lower threshold and is much different from scientific understandings of causation. Generally, to satisfy causation, the legal standard is the "but for" test. The court will say that the defendant caused the loss if it can be determined that the plaintiff's injury would not have occurred, but for the defendant's negligent act. It is well-established that the defendant does not have to be a major cause and that as long as a plaintiff can show the defendant was at least $1 \%$ responsible for the loss, then that defendant can be held fully liable. As such, in a medical negligence case, a patient's legal team might also pursue the hospital, nurses and any other third party that could be at least $1 \%$ liable for the patient's loss. After causation, a court will consider remoteness of the plaintiff's loss and will also evaluate any defences or whether the plaintiff can be partially blamed for their loss, which is referred to as contributory negligence. The burden is on the defendant to prove all elements of a defence.

\section{Canadian content: Canadian Medical Protective Association cases and class action}

In Canada, over 93000 physician members are eligible to receive medicolegal support from the Canadian Medical Protective Association (CMPA) and they maintain a database of over 500000 cases. In Canada, it appears transvaginal mesh cases are not as frequently involved in the courts or complaints' processes as some might believe. According to the CMPA, between 1991 and 2011, there were only 23 closed cases against physicians which involved vaginal mesh procedures (both MUS and transvaginal prolapse mesh procedures). ${ }^{7}$ Of the 23 cases, 19 involved legal matters and the remaining cases were related to complaints against a physician to their College. The majority of those cases (20) were against gynecologists, compared to only three of those cases being against urologists. In terms of the dispositions of the cases, $61 \%$ of the reported incidents, both legal cases and regulatory College cases, were dismissed. A smaller portion of the cases resulted in settled legal outcomes and only one case resulted in a judgment in favour of a doctor. The CMPA stated that the "most common mesh complications included bladder or ureter injuries (six cases), postoperative infections (three cases), pelvic pain (three cases), or bowel injury (two cases)." To give readers an idea of the denominator, Welk recently reviewed 59887 patients who underwent SUI treatment with mesh during a 10-year period in Ontario alone. ${ }^{8}$

In regards to medical negligence and MUS procedures, a provincial court recently found two doctors to be negligent when they perforated a patient's bowel during a tension-free vaginal tape procedure (TVT) to treat the patient's SUI. A staff urogynecologist and an obstetrics and gynecology resident performed the procedure. The issues at trial focused on whether the doctors breached the standard of care and whether informed consent was an issue. The court accepted expert evidence from a urogynecologist and determined that the staff surgeon and the resident doctor's conduct fell below the standard required in the specialty. Despite the procedure being one that is blind, the expert witness testified that "only a careless surgeon would position a TVT trocar so off course that it would cause that kind of injury." The defendants offered counter expert evidence, which provided cases where non-negligent surgeons conducting the same procedure caused similar damage. The defendants also argued that the damage could be a result of atypical anatomy, but the trial judge rejected this possibility, as no facts supported the assertion. The fact that the trocar went off course twice (as evidenced by the damage to the bowel) also corroborated the judge's decision that the surgeons breached their standard of care. Consequently, the court found that the patient's loss "was the result of the resident's handling of the trocar, which makes (them) negligent and this error was not detected by the staff surgeon, which makes (them) negligent [too]." This decision shows that courts hold resident doctors to the same standard and that the law expects a resident's conduct to be the same as a fully qualified doctor of that speciality.

Despite the finding of negligence, the court did not find informed consent to be an issue or grounds for negligence in this case. The informed consent procedure consisted of educating the patient about the procedure with a pamphlet and video at the hospital. The pamphlet and video highlighted various risks, including damage to the bladder and bowel. Additionally, the staff surgeon followed their standard practice regarding informed consent and explained how the procedure was blind, which has inherent risks. The patient argued she would not have consented to the procedure if informed that a resident was participating. In light of this missing information, the court found that a reasonable patient, with the plaintiff's characteristics, would still consent to the TVT procedure. The judge decided this 
by calculating the potential deleterious impacts from the particular procedure with the expected benefits of treating her SUI. Therefore, the court was of the view that the patient would still have consented if it were disclosed that a resident was participating in the surgery.

The doctors appealed the case, but the Court of Appeal did not find any reasons to interfere with the trial judge's decision. This case appears to be one of the most recent decisions where a court has found surgeons to be negligent with MUS procedures. Given the limited jurisprudence in this area, this case is important for MUS procedures and will likely guide other courts when future cases of medical negligence and MUS procedures arise.

In Canada, there are several class action lawsuits pending against transvaginal mesh companies. Many of these stem from allegations that several companies did not sufficiently warn patients and doctors about the dangers of transvaginal mesh used in MUS procedures. Currently, Canadian class action lawsuits have been commenced against different companies including Johnson \& Johnson, American Medical Systems, ${ }^{9}$ Boston Scientific, ${ }^{10}$ and Coloplast and Covidien. The class action against Coloplast terminated in July 2016 when the company offered to settle specific claims with patients on individual levels, while still refuting liability.

While courts have recognized the legitimacy of classes of plaintiffs in some cases, other class actions are battling for certification or to prove that the classes of plaintiffs are legitimate. In many of the actions against the medical mesh companies, a common legal hurdle that arises is that the class, or multiple plaintiffs alleging negligence, do not experience similar issues or are not in similar enough positions as a result of the MUS products. Consequently, the difficulties with certifying large class actions have led to some plaintiffs pursuing the tort actions individually or in smaller, more targeted class actions. For instance, one recent case is O'Brien, where the initial class action against the medical mesh company Bard failed, as there were too many categories and the class did not have enough similarities in their issue with the product. ${ }^{11}$ To respond, the plaintiffs limited the class to patients who used Bard's Avaulta's "Align or Adjust" products to manage POP and SUI. After reducing the class the action was successful and the court agreed to a $\$ 2.475$ million settlement for the class members. Accordingly, the success of recent cases gives weight to the controversial issues that exist with transvaginal mesh products.

The situation in the U.S. (which Canadians are often exposed to while watching American TV featuring 1-800-DIAL-A-LAWYER advertisements), is quite different. Over 90000 women have joined class action lawsuits as result of complications from transvaginal mesh placement. ${ }^{12}$ While most of these lawsuits have focused on the companies producing the mesh products, some of the juries have assigned a portion of the liability to the physician. There is evidence that some US health insurance companies are contacting women within their network who have had transvaginal mesh surgery, and then staking a claim to a portion of any future legal settlement in order to reimburse the insurance company for the healthcare costs associated with treatment of any mesh complications. Other companies have gone even further, and released information on women who have transvaginal mesh placed to third-party companies responsible for recruiting litigants for class action lawsuits. ${ }^{12}$

It seems that more cases involving MUS medical negligence and manufacturer liability will be decided in the near future and this could have tremendous implications for physicians and women seeking treatment for SUI.

\section{Reducing your risk?}

It would be unfortunate to return to the time before MUS, but worry about mesh and litigation has driven some surgeons to make that decision. In a recent communication with the CMPA, they have some "risk messaging" for surgeons performing MUS: ${ }^{7}$

1. The consent discussion should contain appropriate information on the risks (e.g., mesh failure, need for revisions) and benefits of the proposed intervention, alternative options and possible complications of the intervention. The patient should be given the chance to ask questions and the discussion should be adequately documented in the medical record.

2. Consider whether additional diagnostic tests or consultation are necessary to establish or confirm the diagnosis.

3. Consider medical management for patients prior to a surgical intervention (e.g., pelvic floor exercises, use of pessary).

4. Ensure that the operative report includes details of the surgical technique, anatomical findings and variants, difficulties encountered in the procedure, and confirmation that sponge and instrument counts were correct.

5. Ensure that the patient's medical record is accurate, contemporaneous and contains the complete clinical information written in a clear, legible manner. Include rationale supporting decisions regarding the proposed treatment plan.

In discussing with MUS surgeons, many use CUA pamphlets, give out the CUA Mesh Statement, ${ }^{4}$ use their own "homemade" literature or direct patients to online information. This is an important step, given a significant proportion of women forget even basic parts of the consent process within six weeks, such as the fact that vaginal mesh will be used in their procedure and that there is a risk of vaginal or urethral erosion. ${ }^{13}$ Ultimately, the consent discussion comes down to documenting the conversation and the sur- 
gery comes down to performing it at the highest standard and managing complications as expeditiously and expertly as possible.

Competing interests: Mr. Hengel is a second-year law student rather than a licensed and insured lawyer and, as such, the information provided in this article does not constitute legal advice. The remaining authors report no competing personal or financial interests relevant to this review.

This paper has been peer reviewed.

\section{References}

1. FDA and CDRH. Urogynecological surgical mesh: Update on the safety and effectiveness of transvaginal placement for pelvic organ prolapse. Published July 2011. Available at: https://www.fda.gov/downloads/MedicalDevices/Safety/AlertsandNotices/UCM262760.pdf. Accessed April 1, 2017.

2. Health Canada. Surgical mesh - Complications associated with transvaginal implantation for the treatment of stress urinary incontinence and pelvic organ prolapse - Notice to hospitals. Available at: http://www.healthycanadians.gc.ca/recall-alert-rappel-avis/hc-sc/2014/39475a-eng.php. Accessed April 1, 2017.

3. AUGS and SUFU. Position statement on mesh midurethral slings for stress urinary incontinence. Available at: http://sufuorg.com/docs/guidelines/augs-sufu-mus-position-statement-approved-1-3-2014.aspx. Accessed April 1, 2017.
4. AUA. AUA position statement on the use of vaginal mesh for the surgical treatment of stress urinary incontinence. Available at: https://www.auanet.org/education/vaginal-mesh-for-sui.cfm. Accessed April 1, 2017.

5. CUA. CUA position statement on the use of transvaginal mesh. Published July 2016. Available at: http://www.cua.org/themes/web/assets/files/cua_position_statement_on_transvaginal_mesh_ v4_np.pdf. Accessed April 1, 2017.

6. Robert M Solomon, Mitchell Mclnnes, Erika Chamberlain \& Stephen Pitel, Cases and Materials on the Law of Torts, 9th ed (Toronto: Carswell, 2015).

7. Personal Correspondence with Dr. Lisa Calder, Director, Medical Care Analytics, Canadian Medical Protective Association, Feb 21, 2017

8. Welk B, Al-Hothi H, Winick-Ng J. Removal or revision of vaginal mesh used for the treatment of stress urinary incontinence. JAMA Surg 2015;150:1167-75. https://doi.org/10.1001/jamasurg.2015.2590

9. Ontario Superior Court of Justice. Available at: https://www.canlii.org/en/on/onsc/doc/2015/201 5onsc3434/2015onsc3434.html? resultindex=1). Accessed April 1, 2017.

10. Ontario Superior Court of Justice. Available at: https://www.canlii.org/en/on/onsc/doc/2015/201 5onsc7950/2015onsc7950.html? resultindex=1). Accessed April 1, 2017.

11. Ontario Superior Court of Justice. Available at: http://www.canlii.org/en/on/onsc/doc/2016/20160 nsc3076/2016onsc3076.html?autocompleteStr=0'Brien\%20v\%20Bard\&autocompletePos=2. Accessed April 1, 2017.

12. Perkins CE, Warrior K, Eilber KS, et al. The role of midurethral slings in 2014: Analysis of the impact of litigation on practice. Curr Bladder Dysfunct Rep 2015;10:39-45. hitps://doi.org/10.1007/s1 1884014-0278-z

13. McFadden BL, Constantine ML, Hammil SL, et al. Patient recall 6 weeks after surgical consent for midurethral sling using mesh. Int Urogynecol J 2013; 24:2099-104. https://doi.org/10.1007/ s00192-013-2136-5

Correspondence: Dr. Richard J. Baverstock, vesia [Alberta Bladder Centre] and Section of Urology, Department of Surgery, University of Calgary, Calgary, AB, Canada; richard.baverstock@ahs.ca 